\title{
Correspondence
}

\section{Importance of social workers in the training of child psychiatrists}

DEAR SIRS

We are writing to bring to the attention of the College the detrimental effects that the withdrawal of social workers from child psychiatry departments will have upon the training of child psychiatrists. In recent months there have been attempts, some of which have been successful, to redeploy social workers from multi-disciplinary child psychiatry teams to understaffed area offices. In child psychiatry departments social workers, with their particular training and accumulated experience, are an essential asset. Their importance for clinical services has been acknowledged elsewhere. Here we wish to explain why they have a role in training child psychiatrists.

Firstly, social workers have a training which includes the study of social administration, including the institutions of welfare and child care law. They are familiar with the local authority and judicial decision-making processes concerning children, care issues and social service departments. They contribute to the teaching, both formally and informally, concerning child care issues.

Secondly, they are usually trained in non-clinical settings and are employed by social service departments. Their model for working, the social model, is often different to that of psychiatrists. Since child and adolescent psychiatry requires consideration of the whole range of conceptual models, their contribution is, in clinical settings, complementary to good practice. In practical terms, the withdrawal of social workers from child psychiatry teams may mean that the other team members feel unable to accept referrals of patients with particular kinds of problem. This in turn may lead to a narrowing of senior registrars' clinical experience.

Thirdly, in many child and adolescent psychiatry teams the social workers are the most experienced and skilled family therapists. Co-therapy and supervision provide good opportunities for learning family therapy skills. Outside the post-graduate training institutions, and especially outside London, access to family therapy teaching and supervision for trainee child psychiatrists is limited. Furthermore, social workers often have specialised skills in other treatment techniques which contribute to senior registrar training.

Fourthly, in teaching hospitals especially, there is a rapid turnover of junior staff, and this means that permanent team members, such as social workers, have an important role in maintaining and transmitting the team ethos. How this happens is something which senior registrars, who regularly change teams to gain experience, have to learn for their work as consultants.

The threat to the place of social workers in psychiatric teams is occurring at a time of change in the organisation of education. One notable example is the uncertainty over the future of the Inner London Education Authority. This must place in doubt the future of London's child guidance clinics, where many trainees gain experience of multi-disciplinary work with social workers and other professionals. Furthermore, the uncertain future of ILEA also casts doubt over the participation of teachers in child psychiatry teams. Sadly, the trend appears to be towards greater homogeneity within child psychiatry teams, in that the professionals will tend to have received similar trainings and be employed by the same authority.

The importance of multi-disciplinary work in the training of child psychiatrists is recognised in the Child and Adolescent Psychiatry Specialist Advisory Committee (CAPSAC) recommendations that "trainees should have experience of working in a variety of settings and with the full range of related disciplines". We urge the College to apply pressure to the DHSS and other bodies so that its recommendations may be fulfilled. Without such changes a new generation of child psychiatrists will emerge who have had no experience of working in a multi-disciplinary team. The College will be considered to have failed in its responsibilities if the CAPSAC recommendations are amended merely to reflect the changed opportunities in training.

MatTHEW HODES

Adrian ANGOLD

RACHEL BROWN

Ruth Alloway

MARK BERELOWITZ

PATRICK BOLTON

RICHARD EYRE

Prainees in Child and Adolescent Psychiatry

The Maudsley Hospital and King's College Hospital

London SES

\section{Community nurses in child psychiatry}

DEAR SIRS

The child psychiatrists in the Wessex Region have been considering the establishment of CPNs in the 